\title{
ENSINAR LITERATURA ALÉM DO CÂNON E DOS MANUAIS DE LEITURA
}

\section{Albino Chacōn Gutiērrez *}

Resumo: Nossas práticas de ensino de literatura com os jovens não têm seguido ou não têm claras as funções que deve ter hoje a literatura. O ensino médio tem levado a cabo a ideia, não de que os jovens leiam literatura, mas que devem estudá-la, no sentido de adquirir conhecimentos da historiografia literária, tendências, movimentos, estilos, períodos ou a literatura como auxiliar da gramática. Estamos longe de pensar que, quando falamos em "ensinar literatura", falamos de cumprir nas nossas aulas com um programa no qual a leitura e a interpretação dos textos se reforça com os manuais de leitura e resumos que se encontram em qualquer lugar, além de avaliações com definições e respostas já prontas, que os estudantes aprendem de memória para efeitos unicamente de promoção. Nesse contexto, nosso objetivo, neste artigo, é apresentar posições alternativas que permitam abrir uma discussão no campo da educação literária, assim como a possibilidade de incidir nas políticas e decisões educativas e nos perguntarmos: com nossas práticas de ensino estamos ajudando a formar leitores ou, pelo contrário, estamos evitando?

Palavras-chave: Ensino de literatura. Cânon de leituras. Juventude. 


\section{INTRODUÇÃo}

$\boldsymbol{M}$ ais que uma disciplina, o estudo da literatura é uma transdisciplina, o que implica que seu ensino tenha uma natureza articuladora com outros discursos e saberes, como a história, a psicologia, a política, a filosofia, ou seja, com tudo aquilo que está ligado à nossa condição de seres sociais. A literatura funciona como um campo de luta, de tensões, de forças em disputa, de condensação textual das contradições pessoais e sociais. Por esse papel plural da literatura na vida de indivíduos e nações, não é por acaso que muitos afirmam, convencidos, que um livro mudou suas vidas; ou em outra dimensão, na vida política das sociedades na América Latina, os escritores estiveram entre os primeiros a serem perseguidos quando alguma ditadura chegou ao poder, dada a energia mobilizadora, transformadora, conscientizadora inerente à literatura.

No entanto, nossas práticas de ensino de literatura aos jovens não têm seguido ou não têm claras essas funções. O ensino médio tem levado a cabo a ideia não de que os jovens leiam literatura, mas que devem estudá-la, no sentido de possuir conhecimentos da historiografia literária, tendências, movimentos, estilos, períodos ou a literatura como auxiliar da gramática.

Nesse contexto, nosso objetivo é apresentar posições alternativas que permitam abrir uma discussão no campo da educação literária, assim como a possiblidade de incidir nas políticas e decisões educativas que estão relacionadas com uma dimensão tão fundamental na vida como é a literatura. Para isso, questionamos se com nossas práticas de ensino estamos ajudando a formar leitores ou, pelo contrário, os estamos afastando dos livros.

A primeira ideia que temos que revisar é a antiga, porém persistente, noção da literatura como expressão essencial das "belas letras", porque isso tem gerado um problema de enfoque, afetando as metodologias de ensino e contribuindo para a desativação - ou abertamente a exclusão - de muito da literatura que se produz fora do cânon aceitado. Existe uma tendência de estudar a literatura partindo do que é próprio dela, o que a transforma em um produto estético - sejam as figuras literárias ou retóricas -, e a reduz a um campo cheio de metáforas, metonimias, hipérbatos, anáforas, catacreses, prosopopeias, hipérboles, eufemismos ou litotes.

Frequentemente, exige-se dos estudantes a capacidade de distinguir umas das outras, encontrá-las, classificá-las. Nesse sentido, é comum aparecerem avaliações do tipo: "assinale quatro metáforas, três símiles, duas hipérboles e uma anáfora". Somente um péssimo poeta escreveria seus textos pensando em preenchê-los com uma figura retórica atrás da outra, como se disso se tratasse o exercício poético. Em nossas aulas de literatura, no lugar de criadores de visões alternativas da vida, do futuro e da sociedade, de seres humanos em busca de diálogos enriquecedores com o que leem, é possivel que estejamos formando sujeitos com mentalidade fragmentada, incapazes de interpretar criativamente um texto, sem imaginação, sem o livre jogo das ideias, normalmente perturbadoras, que a leitura sempre deve possibilitar.

A segunda ideia é a concepção do papel didático da literatura de ser exemplo das normas de bom uso da linguagem, o que tem se relacionado não só com a maneira como têm sido elaborados os manuais de leitura para o ensino médio, 
mas também com a seleção das obras, ou seja, com o cânon escolar de leituras, que inclui umas e exclui outras. E essa seleção acontece conforme o grau de desconfiança que se tem, por um lado, da probidade e formação dos professores e, por outro, da maturidade e sensatez dos jovens. Deixemos de lado a ideia de que hoje a leitura está em crise, de que não há leitores, ou o juízo de que os jovens de hoje em dia não leem. É verdade, sim, que seus interesses de leitura são outros e pouco têm a ver com aquelas obras que fazem parte do cânon escolar.

\section{O conto gue contamos}

O romance, a poesia ou o drama criam uma realidade, e sua relação com a realidade externa é oblíqua, sugestiva, indireta, insinuante, isto é, ficcional, o que não tem nada a ver com falsidade. Os historiadores atuais estão convencidos de que os acontecimentos não são externos ao discurso que trata deles, já que a história é, em si mesma, uma construção discursiva, uma narração e, portanto, não é alheia ao carácter ficcional ${ }^{1}$. A literatura, por sua vez, não pretende contar a verdade, ainda que busque a verdade por meio da ficção, não na ordem da veridicção, mas da verossimilhança, mediante as coordenadas de relações que provoca.

As coisas não têm forma própria, têm a forma que lhes damos com as palavras. A partir desse conceito, deriva-se um princípio epistemológico de profunda importância no ensino de literatura com o qual concordamos: o saber não é factual, mas uma construção que cada sujeito deve aprender a efetuar.

Estamos longe de pensar que, quando tratamos do "ensinar literatura", falamos de cumprir, nas aulas, um programa no qual a leitura e a interpretação dos textos se reforçam com os manuais de leitura e resumos que se encontram em qualquer lugar, além de avaliações com definições e respostas já prontas, que os estudantes aprendem de memória para efeitos unicamente de promoção.

Há uma terceira ideia de que o modo como se organiza o trabalho educativo é um exercício político. No sistema educativo, passamos do aprisionamento dos sentidos à repressão de um só passo, e, com interpretações pré-fabricadas, estamos formando cidadãos sem critério. Poderiamos estar traindo, dessa forma, a essência mesma da educação, que não pode ser senão a de preparar os alunos para o exercício pleno de uma cidadania crítica e criativa.

Ser provocadores de discursos é o único modo pelo qual os alunos se transformam em sujeitos com voz própria, e não em repetidores de saberes que lhes são alheios. Fazer com que os alunos sejam voz e não eco deve ser a regra que guia o trabalho com eles, para que o modo como leem permita que criem seus pequenos universos de sentidos, universos quiçá com equilíbrios precários, cambiantes, provisórios, porém, seus. Precários porque sempre estão em movimento, se fazem e se desfazem, mas quem disse que isso constitui um problema? Acaso não tem sido essa a história mesma da interpretação literária?

\footnotetext{
Diversos historiadores têm insistido nessa característica do discurso histórico, particularmente, Hayden White em seus diversos livros. Em El texto histórico como artefacto literario, por exemplo, ele afirma: "O problema principal para qualquer teoria do escrito histórico não reside, portanto, na possibilidade ou impossibilidade de uma aproximação científica ao estudo do passado, mas sim, em explicar a persistência da narrativa na historiografia. Uma teoria do discurso histórico deve atender à questão da função da narratividade na produção do texto histórico. Devemos partir então do irrefutável fato histórico do qual os discursos distintivamente históricos produzem de modo característico interpretações narrativas de seu tema de estudo" (WHITE, 2003, p. 145). Mais próximo de nós, o tema da relação história-literatura está no centro do debate no livro compilado por Ana Paulina Malavassi (2006), Historia: ¿ciência, disciplina social ou prática literária?.
} 
Não deixa de ser uma contradição que, na história da interpretação, tenhamos evoluído e dado passos gigantescos, desde a hermenêutica bíblica dos padres da igreja, quando tentavam fixar um sentido único dos textos provenientes, em última instância, de um Deus a quem se considerava a fonte e o destino de todo o sentido. Posteriormente, chegariamos à teoria da recepção, com o leitor no centro da produção de novos e contraditórios sentidos do texto; ou, mais recentemente, às teorias desconstrucionistas, cuja contribuição fundamental consiste na descentralização do sentido mesmo da obra literária, ao deixar de considerá-lo uma essência, uma centralidade dominante e excludente.

Todo texto é sempre um artefato cheio de portas e janelas abertas, nunca uma sala fechada, em que, às vezes, transformamos nossas salas de aulas, num tirânico exercício de poder, que se complementa com o sistema de prêmios e castigos: as provas. Os sentidos não são objetos de museu, estátuas sujeitas à mera contemplação e admiração, mas sim móveis, instáveis, vacilantes, frágeis. A situação se agrava quando já não é o professor, mas o próprio sistema educativo oficial que promove e incita esse tipo de aprendizagem e castiga o livre jogo das interpretações, o ato mediante o qual professor e aluno estabelecem uma relação de diálogo pessoal com os textos que leem.

Eu faço perguntas ao texto, porém ele também me faz perguntas. A partir dessa experiência, quem lê se transforma e constrói as bases de sua subjetividade, e, por meio dela, chegamos a ser homens e mulheres que, a partir do diálogo com os demais e com as grandes tradições históricas e contemporâneas, construímos nosso eu pessoal, nosso ser social e nossa cultura.

\section{Procura-se UM OlHAR NA LITERATURA}

Estamos constantemente enviando e recebendo mensagens: com nossa voz, com nossa maneira de vestir, com nossos gestos, com os meios tecnológicos que temos a nosso alcance, em busca de um olhar capaz de ler nossas necessidades, nossos medos, nossas inseguranças e desejos, em suma, um olhar que saiba nos interpretar e graças ao qual estejamos em condições de constituir nossa humanidade. Um olhar que, com certeza, muitos jovens não encontram no mundo de hoje.

Essa ideia tem atravessado a literatura de todos os tempos e constitui a base essencial de nossa relação com ela e dela conosco. Não estamos falando do texto literário como unidade, como estrutura linguística coerente de verbos, substantivos e advérbios, de predicados e complementos, ou como um exemplo de correto uso gramatical. Isso é o que normalmente esquecemos ao estudar com nossos alunos a literatura, que temos que ver como espaço de sentidos em luta, mediante os quais uns sujeitos se confrontam, se relacionam, se odeiam e se amam, tentando se constituir. A literatura é a alquimia que produz essas transformações.

Quem leu El Túnel, de Ernesto Sábato (1948), recordará a passagem fundamental: Juan Pablo Castel é um pintor que exibe uma exposição. Sua atenção se concentra nos visitantes que se detêm diante de um dos seus quadros, um só de toda a exposição. Castel analisa o que cada um observa nele; nenhum dos olhares previsiveis que veem seu quadro de maneira geral lhe interessa, porque não conseguem se fixar no detalhe que ele quer que descubram. Até o momento 
em que chega Maria, que se detém diante do quadro e, ao contrário de todos os demais, apenas chega à frente dele, detém seu olhar naquele ponto que Castel queria que se olhasse, porque esse ponto é o que para ele sintetiza todo o sentido de sua pintura.

Esse olhar é o texto básico que subjaz na imensa maioria das mensagens que enviamos todos os dias de nossa vida.

O exposto até aqui quer dizer muitas coisas, porém há uma em particular: um sujeito é sujeito quando conta com um discurso próprio, quando tem uma voz que se sente autorizada, isto é, se a educação lhe oferece a possibilidade de se transformar em hermeneuta de si mesmo. Nesse panorama de exigências que lhe pedimos para o ensino de literatura, que papel desempenham as avaliações de múltipla escolha, as provas de dupla, as perguntas com espaços em branco que devem ser preenchidos ou as de falso ou verdadeiro? Como pode ser que para as aulas de literatura - ou para as de história - se promova esse tipo de avaliações por parte dos diversos agentes educativos? Ken Robinson (apud SILIÓ, 2003) afirma:

Ao professor só lhe interessa que se responda o que está nos conteúdos do programa, o que causa frustração naqueles alunos que se arriscam mais e naqueles que gostam de improvisar. Isso permite que cada vez se atrevam menos a pensar de maneira diferente por medo de se equivocar.

Falamos da literatura como uma atividade criativa, no entanto o modo como nos aproximamos dela normalmente não permite ao aluno - nem o professor permite-se a si mesmo - produzir discursos alternativos. Por isso, é dificil entender a tendência de transformar todos os textos, incluindo os literários, em bancos de dados, que inviabilizam a criação de conhecimentos estruturados e significativos para os alunos.

Quais leituras se escolhem hoje? É verdade que devemos conhecer os clássicos, e perderíamos muito ao não lermos Homero, Shakespeare, Dante, Cervantes e outros que fazem parte do grande cânon ocidental. Entretanto, também perderíamos muito ao não lermos os contemporâneos, que estão escrevendo a literatura que nasce do contexto no qual estamos vivendo e que falam justamente de nós, de nosso momento histórico.

É a literatura contemporânea uma escrita "do bom dizer", educada, bem falada, sem más palavras, que desenvolve temas e uma linguagem à prova de qualquer censura? Provavelmente não. Muitas vezes, não. No entanto isso não é o essencial: a boa literatura é utopia, esperança, expectativas, alegria, regozijo, nascimento, mas também é sexualidade, terror, violência, más palavras, morte, dor, ou seja, a vida mesma e, como ela, expressa também o lado terrivel próprio da cultura humana. A literatura é como uma praça na qual confluem o melhor e o pior, onde convergem a violência e a crueldade, mas também os maiores valores da humanidade. A literatura que se escreve hoje e, de maneira particular, na América Latina, se nutre de diversas fontes, gêneros, subgêneros e estilos que não têm medo de se mesclar. A literatura é o que é a vida: um carnaval grotesco e, ao mesmo tempo, uma celebração divina. 


\section{OUTRO CÂNON É POSSÍVEL}

Os jovens têm seu próprio cânon de livros $^{2}$, formado por sagas de magos, vampiros, demônios e, sobretudo, ficções apocalipticas do mundo de hoje e de amanhã, ao redor das quais se formam inclusive clubes de leitura. Essas obras têm em comum o fato de apresentar histórias posteriores à destruição da sociedade, com adolescentes que lutam contra governos que tomaram o poder depois de guerras ou catástrofes mundiais. O fato de serem livros nos quais os heróis principais são jovens torna as histórias mais atrativas. Como assegura um jovem, a obra Jogos vorazes, por exemplo, "mescla o amor não correspondido, a realidade de um Estado corrupto, a valentia de uma jovem que tem que brigar e tentar sobreviver". Segundo uma leitora jovem, o que chama a atenção na trilogia Divergente é a importância que ela dá à capacidade que os jovens têm de tomar decisões, de crer em si mesmos e de vencer seus medos. Esses jovens compartilham muitíssimo suas leituras nas redes sociais.

É verdade que, por trás desses livros, existem gigantescas agências editoriais que se encarregam de que não sejam simplesmente livros, mas bens de consumo sumamente atrativos. Porém, muito além dessa consideração, tratam-se de romances que recolhem paixões universais e reelaboram temas que têm sido tradicionalmente tratados na literatura de todos os tempos. Uma jovem salienta que podia passar noites inteiras lendo sobre sociedades fictícias de um futuro opressor, porém no colégio foi incapaz de ler um livro de leitura obrigatória.

Esses livros, muitos dos quais são extensas trilogias, mostram vários aspectos pelos quais se pode chegar a interessantes conclusões. Por um lado, não é certo que a leitura esteja em crise. Os jovens leem com fruição e entusiasmo livros que constituem um universo à parte das leituras impostas pelo sistema educativo e que ainda não há permeado o cânon escolar de leituras.

Estamos, portanto, diante de duas dimensões da leitura que se comportam como compartimentos estanques, divididos por gerações. Na base dessa confrontação, encontramos o preconceito de que se trata de best sellers e, por conseguinte, obedecem à ordem da literatura de massa, de uma subliteratura, que, na maioria dos casos, não seria mais que expressão do imperialismo cultural, com grande êxito de penetração de práticas publicitárias dos grandes consórcios editoriais internacionais, especialmente os norte-americanos. Nesse contexto ideológico, há quem considera que o sistema educativo deveria ter como função proteger nossa juventude do consumismo dessas influências que atentam contra nossa produção literária, contra o conhecimento de nossos autores e contra os valores de nossa identidade cultural. Dessa forma, com certeza, não há diálogo possivel.

É deixado de lado o fato de que os temas e motivos que desenvolvem esses livros são os mesmos que vêm sendo tratados nos clássicos da literatura ocidental, para não mencionar o conto maravilhoso europeu, o romance gótico ou o romance de aventura do século XIX, bem como outras tradições literárias. Por isso, a desqualificação apriorística não cabe. Trata-se, dessa forma, de um novo cânon que funciona em condições muito distintas das tradicionalmente observadas até boa parte do século XX, e não só por parte do mercado, porque os

2 Os dados e citações em relação à preferência de leitura dos jovens, assim como a citação de Carlos Rubio, foram retirados do artigo "O fim do mundo jovem", de Ester Vargas Ramírez (2014). 
referentes culturais, as formas de socialização e de comunicação dos jovens, seus interesses, parecem ir por rumos distintos daqueles que têm em mãos a organização dos programas oficiais de ensino de literatura.

Interessa-me ressaltar um livro próximo e polêmico da literatura costa-riquenha contemporânea, para ilustrar como exemplo concreto as possibilidades interpretativas do que venho tratando de explicitar. Quando apareceu na Costa Rica, o romance Bajo la lluvia Dios no existe, de Warren Ulloa (2011), foi classificado como obra imoral, antirreligiosa, de linguagem chula e pornográfica. As pessoas não entendiam como uma obra literária dessa qualidade, um mau exemplo para a juventude, recebera o Prêmio Nacional de Literatura. E, no entanto, suas duas edições se esgotaram rapidamente.

Bajo la lluvia Dios no existe apresenta uma visão perturbadora da sociedade atual, em particular da juventude. A obra gerou um forte impacto ao mostrar em suas páginas o beco sem saída para o qual estão conduzindo os jovens os aparelhos que se ocupam deles e que estão fracassando de maneira absoluta: o Estado, a educação, a família. O não entendimento disso quando lemos o romance deixa de lado os diversos niveis de sentido sob sua iconoclasta superfície linguística. Ater-se somente ao título ou desqualificar a obra, pela utilização de uma linguagem imprópria e pela descrição explícita de práticas sexuais, significa deter-se no nivel mais elementar do texto.

O título do livro, em vez de servir de estímulo para a leitura e significância do texto, o bloqueia logo de entrada. De que Deus se trata e qual é a chuva que apaga sua existência? A menção a Deus não se refere - ou não deveria se referir única e necessariamente - à noção religiosa. Temos que vê-la como uma noção ligada às figuras do poder, ao mundo do simbólico, à figura do Pai, da Lei, ao mundo da Cultura e, finalmente, às figuras nas quais esse poder se transfigura e por meio das quais se faz representar. Esse é o Deus contra o qual, de maneira lúdica e consciente, se revela o personagem feminino de Mabe. Só parcialmente, é claro, porque ao final a figura da Lei, do Pai, articulada numa das formas principais - seu pai biológico, incestuoso e corrupto - a leva ao suicídio.

Suicidar-se é a maneira radical de matar o Pai, como um ato de limpeza. Por isso, a figura de um haraquiri é escolhida por ela mesma como capa do livro de poemas que escreve. O desenho do haraquiri atua, desse modo, como a chave de interpretação que deixa sobre o suicídio.

O romance mostra todos os demônios que rodeiam a vida contemporânea dos jovens: sexo, droga, narcotráfico, consumismo, incesto; corrupção política, prostituição e, inclusive, a violência das torcidas de futebol. Essa trama de violência constitui a cara plural e visivel do funcionamento das práticas sacrificiais cujo bode expiatório são os jovens. O que fica? Para Mabe e, finalmente, também para Bernal - qual versão do século XXI de Romeu e Julieta -, só resta o último gesto de dignidade possivel: a morte. O único líquido que limpará Mabe não é a chuva que, como leitmotiv do romance, cai sobre ela como vão ato supletório de limpeza. O líquido que a limpará é aquele que sairá dela mesma: seu sangue.

Assim, Bajo la lluvia Dios no existe é um romance de iniciação, de aprendizagem, mas o que ensina aos adolescentes é que, assim como está, com todas as estruturas de poder e de violência que enfrentam, próprias de uma sociedade produtora de constantes vítimas sacrificiais, além do rock e da literatura, a vida talvez não valha a pena ser vivida. 


\section{OS ESTUDOS LITERÁRIOS: UM CAMPO INSTÁVEL}

O ensino e o estudo da literatura requerem revisar o conceito mesmo do que entendemos como tal e proceder de acordo com uma atualização, a partir das novas relações e configurações discursivas que o funcionamento da instituição literária estabelece com a chamada cultura popular, com a cultura de massa e com os meios de comunicação nas novas e inéditas condições de distribuição, de consumo e de produção atuais. Os jovens, em particular, vivem em um mundo com perspectivas e horizontes planetários distintos. Seus princípios, medos, capacidade e desafios são outros, bem como seus gostos e também os valores éticos e estéticos que esperam encontrar nos produtos artísticos que consomem.

Outro tema importante está relacionado à necessidade de se abrir o cânon de leituras a novas identidades particulares de grupos específicos, que hoje estão mais disponiveis a diferentes possibilidades identitárias, com margens de liberdade inéditas em nossas sociedades. Referimo-nos à literatura que aborda o tema das múltiplas identidades sexuais. Sua visivel presença the confere um valor enunciativo imprescindivel e um caráter politicamente provocador, por isso é importante sua inclusão no universo de leitura dos jovens.

Os estudos sobre literatura encontram-se hoje em um estado de grande instabilidade, devido à abertura suscitada no cânon tradicionalmente compreendido como literário, dadas as novas condições de produção e difusão. Essas novas literaturas têm, entre suas características intrínsecas, uma grande fluidez de fronteira e grandes possibilidades de entrecruzamentos discursivos, "instabilidade" que não deve ser vista como perda, mas como ganho. Essa condição de ser inapreensível em uma definição unívoca é sua grande riqueza, produto das mil caras nas quais a literatura pode se desdobrar. A esse respeito, cabe citar o que um músico escreveu a propósito do Jazz, aplicável à literatura:

Querem definir fixamente ojazz com base no que ele foi, como se ele alguma vez tivesse sido fixo. O jazz nasceu de nuanças, de variantes e, partindo desse ponto, nunca mais voltou a ele. Ojazz está sempre indo para frente. O jazz nunca vai voltar para atrás ${ }^{3}$.

Essa descentralização vivida pelo jazz é também vivida pela literatura de hoje, não tem volta e, nesse sentido, exige que o ensino da literatura esteja em dia com essa nova produção literária, se não quiser se tornar obsoleto.

\section{Teaching Literature beyond THE CANON AND Reading ManUals}

Abstract: Our practices of teaching literature to young people are unclear or have not followed the functions that literature should have today. High school has not carried out the idea that young people read literature, but they must study it, in the sense of possessing knowledge of literary historiography, trends, movements, styles, periods, or literature as an aid to teach grammar. We are far from thinking that when we talk of "teaching literature", we are referring to attending classes with a program in which the reading and interpretation of texts is reinforced by manuals and abstracts that are found everywhere, besides

3 Icons among us: jazz in the present tense, de Lars Larson e Michael Rivoira (cf. GONÇALVES, 2010, p. 100). 
evaluations with all ready-made definitions and answers that students memorize for promotional purposes only. In this context, our aim in this article is to present alternative positions that allow us to open a discussion in the field of literary education, as well as the possibility of focusing on educational policies and decisions that are related to such a fundamental dimension in life. We must asked ourselves about our teaching practices: Are we helping to train readers or, on the contrary, are we avoiding it?

Keywords: Teaching Literature. Canon. Youth.

\section{REFERÊNCIAS}

GONÇALVES, J. F. Ensino é crítica: a literatura no ensino médio. São Paulo: Nova Alexandria, 2010.

MALAVASSI, A. P. (Org.). Historia: ¿ciência, disciplina social ou prática literária?. San José: Editorial Universidad de Costa Rica, 2006.

RAMíREZ, E. V. O fim do mundo jovem. Revista Dominical, La nación, San José, 2014.

SÁBATO, E. El Túnel. Buenos Aires: Editorial Sur, 1948.

SILIÓ, E. La buena escuela no asfixia la creatividad. El País, 8 abr. 2013.

ULlOA, W. Bajo la lluvia Dios no existe. San José de Costa Rica: Uruk Editores, 2011.

WHITE, H. El texto histórico como artefacto literário. Barcelona: Paidós, Barcelona, 2003. 